\title{
Effects of Drought Stress on Crop Production and Productivity
}

\author{
Temesgen Begna* \\ Chiro National Sorghum Research and Training Center, Chiro, Ethiopia
}

*Corresponding Authors: Temesgen Begna, Chiro National Sorghum Research and Training Center, Chiro, Ethiopia.

\begin{abstract}
Stress is a change of the normal growth, development and productivity of crop plants and that is outside the normal range of homeostatic control. Among stresses, abiotic stress is caused due to moisture, temperature, mineral (deficiency/toxicity), salinity, soil acidity/soil $P^{H}$. Drought is the primary cause of crop yield loss among abiotic factors around the world. It is a major problem in world, leading to food shortages and is a challenge for small-holder farmers to produce enough crop grain when rainfall is low and erratic. Climate change is the main cause of biotic and abiotic stresses, which have adverse effects the world's crop production and productivity. Crop production is determined by the existence of sufficient rain fall, especially in areas where crop production is totally relied on rain fall, there is always risk of crop failure or yield loss due to moisture stress. In severe cases, the stress could lead to total crop loss. This day, increasing crop yield is required to meet the needs of increasing population growth, however yield reduction is observed in areas where drought is predominantly devastated crop production. Short duration drought stress mostly reduces grain yield while prolonged drought stress leads to complete death of plant. Drought stress occurs at different stages of growth and adversely affect yield and yield related traits, which lead to reduction in yield. The effect of drought stress is mainly depending on the developmental stage of the plant, degree and duration of the stress, genotypic capacity of species and environmental interactions. Crop plants have adaptation strategies to survive under drought stress by the development of various morphological, physiological and biochemical mechanisms. However, a plant may exhibit more than one strategy to cope with drought stress. Drought resistance is the mechanism(s) causing minimum loss of yield in a drought condition. Drought escape, dehydration avoidance, reduced transpiration or physiological factors are some drought resistance mechanisms. Drought resistant genotypes maintain high photosynthesis under moisture stress condition by restricting transpiration water loss. Finally, the global food security is threatened by climate change and the most challenging in the $21^{\text {st }}$ century to supply sufficient food for the increasing world population. The use of well adapted and high-yielding varieties with resistance to drought stress is important to reach maximum yield potential as long as possible through minimizing the risk of climate change. Climate-smart agriculture is the only way to reduce the negative impact of climate variations on crop adaptation, before it might affect global crop production drastically.
\end{abstract}

Keywords: Drought; Stress; Resistance; Productivity

\section{INTRODUCTION}

Stress is the alteration of physiological, morphological and genetical condition caused by the various numbers of factors that tend to interrupt the equilibrium state (Gaspar et al., 2002). Stress in plant refers to external conditions that adversely affect growth, development and productivity of crop plants (Lerner, 1999). Stresses associated with temperature, salinity and drought, single or in combination, are likely to enhance the severity of problems to which plants will be exposed in the coming decades (Duncan 2000; Cherry et al., 2000). Among Abiotic stresses, drought is a major abiotic stress that contributing a great restriction to agricultural productivity and food production worldwide (Farooq et al., 2009). Drought is the abiotic factor that adversely affects crop plant growth and development, especially in warm and dry areas (Fathi, A et al., 2016). Drought impairs normal growth, disturbs water relations, and reduces water use efficiency in crop plants (Farooq et al., 2009). Drought stress is seriously affecting crop production stability which limits the crop from reaching its yield potential due to erratic and insufficient rain fall. The effect of drought stress is different according to crop varieties, growth stage, level and duration to drought stress (Kato, 2004). 
The effect of drought stress is significantly influences the yield improvement (Forbes and Watson, 1994; Lafitte et al., 2007) and declining crop production generally (Bouman et al., 2005) due to decreasing in growth and photosynthetic rate (Siddique et al., 1999; Zlatev and Lidon, 2012). The environmental conditions such as stresses are the most important yield reducing factors in the world and the crop growth and development are constantly influenced by environmental conditions (Dennis, 2000). Drought is the most important abiotic factor that adversely affects growth and crop production, especially in warm and dry areas (Fathi, A et al., 2016). Agricultural drought adversely affects crop production by reducing leaf size, stem extension and root proliferation, disturbing plant water and nutrient relations, and inhibiting water-use efficiency. There is much yield losses and can potentially result in complete crop failure during the time of severe drought (Mutava et al., 2011). Drought stress is the absence or limited amount of rainfall for a period of time especially during crop growing season and that causes moisture-depletion in soil and followed by a decrease of water potential in plant tissues. It is also characterized by reduction of atmospheric and soil water condition which cause continuous loss of water transpiration and evaporation. Today, drought and salt stresses are the global issues to ensure rapid and sustainable food production through producing adaptive and stable agricultural crops (Jaleel et al., 2007b).

Drought stress is total disturbance of crop metabolism and cellular structure through limiting the availability of sufficient water and which leads to restrict gas exchange as a result of stomatal closure. Extensive and excessive were loss is the syndrome of severe drought, which can potentially lead to gross disruption of metabolism and ultimately to the cessation of enzyme catalyzed reactions (Jaleel et al., 2008). Drought stress is the leading stress to water loss in plants and a big problem in crop yield reduction, especially in areas where predominantly affected by recurrent drought like tropical, semiarid and arid regions of the world. Drought stress is mainly expressed by reduction of metabolic rates, decreasing of water content, decrease leaf water potential and turgor loss, closure of stomata and decrease in cell enlargement and growth. When the water stress becomes severe, the great loss may result in the arrest of photosynthesis, disturbance of metabolism and finally the death of plant (Jaleel et al., 2008c). In addition, drought stresses affect various physiological and biochemical processes like photosynthesis, respiration, nitrogen assimilation, protein synthesis, translocation, ion uptake, carbohydrates, nutrient metabolism, growth promoters and several other processes of crop plants (Farooq et al., 2008). Drought typically lasts for several months to a few years, but extreme drought can persist for several years, or even decades for so called mega-drought (Stahle et al., 2007). It acts as a serious limiting factor in production by preventing a crop from reaching the genetically determined theoretical maximum yield. Climate change is caused due to drought and water shortage is happened, particularly in many African countries that are already drought-prone. For instance, by 2050 , water shortages are expected to affect $67 \%$ of the world's population (Ceccarelli et al., 2004). Climate extremes are expected to increase with climate change and which ultimately devastating the crop production (Troy et al., 2015). Drought stress can cause total risk of crop failure or yield loss, particularly in most areas where crop production is mainly dependent on rainfall. Moisture is always insufficient for crop growth and development in arid and semi-arid tropics areas, due to erratic and recurrent rain fall distribution and poor soil moisture storage capacity.

Water stress could lead to total crop loss which results a big failure in the presence of high food demanding to balance the increasing population growth (Sinha, 1986). Drought is the major limiting factors for yield stability in the semi-arid tropics, where rainfall is insufficient, non-uniform and erratic in distribution (Hamblin et al., 2005). The estimated yield loss each year due to drought was reached around USD 10 billion in the world (Mutava et al., 2011). Crop production and productivity must be increased through different yield boosting mechanisms against abiotic stress in order to meet the needs of future population growth. Water deficiency results from erratic rain fall, less amount of rain fall and when the rate of transpiration exceeds water uptake by plants. The cellular water deficiency is resulted due to the concentration of solutes, loss of turgor, change in cell volume, disruption of water potential gradients, change in membrane integrity, denaturation of proteins and several physiological and molecular components (Grifth and Parry, 2002). Plants developed resistance mechanism against drought stress is crucial through developing different morphological, physiological and metabolic modifications strategies in all organs and therefore traits associated with improved performance under water limited conditions (Slafer et al., 2005). 
The development of resistance varieties with high yield is the main goal in water limited environments; however it is difficult to achieve the maximum success due to the varying nature of drought and the complexity of genetic control of plant responses (Mirbahar et al., 2009). The development of resistant varieties by selecting solely for grain yield is difficult, since drought resistance trait is controlled by many minor genes. Hence, the heritability of yield and yield related traits under drought conditions is low due to small genotypic variance or due to the large variances in the genotype environment interaction (Ludlow and Muchow, 1990; Koszegi et al., 1996). The effect of a single drought adaptive gene on crop performance in water-limited environments can be assessed only when the whole system is considered in terms of yield potential, drought resistance, and water use efficiency. In nature, crop plants are physiologically designed by evolution to increase water use efficiency under drought stress condition. The most important physiological mechanisms to reduce water use are: reduced plant size, leaf area, and leaf area index. In addition to moderate water use, these mechanisms are very critical in decreasing injury under drought stress, (Mitchell et al., 1998). There also other pathways for drought stress resistance mechanism are: reduction in plant size, diminished leaf area, smaller leaves, reduced tillering, and early flowering and the shortening growth duration and reduced leaf number (Blum, 2004). Crop plant growth is greatly affected by drought stress at different morphological levels, particularly shoots and roots are the most affected plant part. The shoot and root are the key components of the plant adaptation to drought stress conditions. Generally, plants limit the number and area of leaves in response to drought stress just to cut down the water budget at the cost of yield loss (Schuppler et al., 1998). The objective of this paper was therefore to understand the effects of drought stress on crop production and productivity and drought resistance mechanism under water limited environments.

\section{Influences of Drought StRess on Crop Plants}

Drought stress is the most important yield decreasing factor by adversely affecting the crop plant growth and development during production season and the negative impact of drought stress is mostly observed in dry and warm areas of the world (Dennis, 2000). Drought stress is the most important abiotic factor which adversely affects crop growth and production. It is the most important environmental stresses that limits crop yield, especially in warm and dry areas (Porudad and Beg, 2003). Drought stress is all about the inadequacy of water availability in quantity and distribution during the life cycle of a crop plant and which restricts the expression of full genetic potential of the plant. Drought stress resulted the reduction of crop plant productivity by reducing the leaf size, stem extension and root proliferation, disturbing plant water and nutrient relations, and inhibiting water-use efficiency. The influence of drought stress on crop plants is currently the leading threat to the world food security which may be a big challenge to meet the food demand.

\subsection{Effect Drought Stress on Photosynthesis of the Plants}

Water stress reduces photosynthesis by decreasing both leaf area and photosynthetic rate per unit leaf area (Boyer J. S, 1976). Water stress severely inhibited and may cease photosynthesis and the reduction of leaf growth under drought conditions may also inhibit photosynthesis in existing leaves, which leads to shortage of food for normal growth and development (Boyer J. S, 1976). Decreasing water content is leading to loss of turgor and wilting, cessation of cell enlargement, closure of stomata, reduction in photosynthesis, and interference with many other basic metabolic processes (Kramer P. J. and Boyer J. S, 1995). Leaf pubescence is increasing under water stress in order to minimize the photosynthesis rates (Ehleringer, 1980). If crop plants are normally unable to get water when required, photosynthesis is affected and transpiration usually decreases at similar rates (Farquhar G. D et al., 1989). The stomatal closure is mainly caused by two factors. The first factor is through increasing in the concentration of gaseous carbon within leaves and the other one is through decreasing in water potential of leaf cells.

Photosynthesis is easily hindered during water stress as a result of stomatal closure and the internal $\mathrm{CO}_{2}$ concentration reduction (Schulze E. D, 1986). Therefore, photosynthesis is decreased in parallel with or more than stomatal conductance (Boyer J. S, 1976). In the water stress condition, the photosynthetic rate in higher plants decreases more rapidly than respiration rate. The effect of water reduction in leaves is usually a partial or complete stomatal closure markedly decreasing the movement of $\mathrm{CO}_{2}$ into the assimilating leaves and reducing the photosynthetic rate up to ten times (Levitt J, 1972). The relationship between photosynthesis and leaf water status is directly proportional 
in ambient $\mathrm{CO}_{2}$ reached a maximum value in the morning and declined later in the day when water potential decreased and leaf to air water vapors pressure deficits increased (Quick et al., 1992).

\subsection{Effect of Drought Stress on Nutrient Uptake}

There are over 100 chemical elements, yet scientists have found that only 17 of them are essential for plant growth and development. In addition to oxygen, carbon dioxide and water, plants require at least 14 mineral elements for adequate nutrition (Mengel et al., 2001). The deficiency in any one of these mineral elements reduces plant growth and crop yields. The six mineral elements, nitrogen $(\mathrm{N})$, phosphorus $(\mathrm{P})$, potassium $(\mathrm{K})$, calcium $(\mathrm{Ca})$, magnesium $(\mathrm{Mg})$ and sulphur $(\mathrm{S})$, are required in large amounts, whereas chlorine $(\mathrm{Cl})$, boron $(\mathrm{B})$, iron $(\mathrm{Fe})$, manganese $(\mathrm{Mn})$, copper $(\mathrm{Cu})$, zinc $(\mathrm{Zn})$, nickel (Ni) and molybdenum (Mo) are required in smaller amounts. Plants generally acquire their mineral elements from the soil solution. Hence, drought stress potentially affects nutrient uptake which leads to unavailability of nutrients for the plant growth and developments.

There are other several stresses which affect the normal growth of plants and the nutrient uptake involved directly to the normal growth and development. Some of the stresses are: These are salinity, flood, plant population, planting time, types of soil, soil organisms, diseases, weeds, toxic metals, air pollution, growth regulators, wind, water-table and allelopathy (Alam, 1999). Drought and salinity are the most differentially affect the availability mineral nutrition of plants. On the other hand, drought can affect nutrient uptake and translocation of some nutrients (Hu and Schmidhalter, 2003). Potassium is a most important nutrients element that has an important role for endurance of plants in stress condition (Baque et al., 2006). The availability of $\mathrm{K}^{+}$to the plant, due to the decreasing mobility of $\mathrm{K}^{+}$ under stress environment, decreases with decreasing soil water content (Arjenaki et al., 2012).

\subsection{Effects of Drought Stress on Morphological Characteristics of the Plants}

It is known that drought stress is a very critical factor in restricting the normal plant growth and development at the initial phase. It affects both elongation and expansion growth (Shao et al., 2008). Among the crops, rice is the most susceptible to drought stress as compared to other plant species. Many studies revealed that soybean stem length is decreased under water deficit conditions (Specht $e t$ al., 2001). The plant height is reduced up to $25 \%$ in water stressed citrus seedlings (Wu et al., 2008). Stem length was significantly affected under water stress in potato (Heuer \& Nadler, 1995): soybean (Zhang et al., 2004). Drought stress suppresses cell expansion and cell growth due to the low turgor pressure. Osmotic regulation enables to assist plant growth under severe drought conditions in pearl millet (Shao et al., 2008).

Decreasing in plant height is associated with a decline in the cell enlargement and more leaf senescence under water stress (Bhatt \& Srinivasa Rao, 2005). The development of optimal leaf area is important to photosynthesis and dry matter yield. Drought stress mostly reduced leaf growth and in turn the leaf areas in many species of plant like Populus (Wullschleger et al., 2005), soybean (Zhang et al., 2004) and many other species (Farooq et al., 2009). Significant inter-specific differences between two sympatric Populus species were found in total number of leaves, total leaf area and total leaf biomass under drought stress (Wullschleger et al., 2005). The leaf growth was more sensitive to water stress in wheat than in maize (Sacks et al., 1997); and sunflower (Manivannan et al., 2007b \& 2008).

\subsection{Effects of Drought Stress on Seed Germinations and Early Seedling Growth}

Seed germination and early seedling growth are potentially the most critical stages for water stress (Ahmad et al., 2009). Many studies on plant responses to drought stress with regard to seed germination and seedling growth have been recently reported, including studies of agricultural crops, Oryza sativa, Avena sativa, Spinacia oleracea, (Ahmad et al., 2009; Chen and Arora, 2011), and grasses, Anthephora pubescens, Heteropogon contortus, Themeda triandra and Medicago sativa (Wang et al., 2009). Seed germination and early seedling growth are critical stages for plant establishment, and plants are more sensitive to drought stress during these stages (Li et al., 2011).

\subsection{Effect of Drought Stress on Yield and Yield Related Traits of the Plants}

The relationship between grain yield and yield related traits with drought stress were determined by correlation matrix (Kumar et al., 2012). Grain yield is positively correlated with biomass, harvest index and weight under drought stress condition whereas leaf rolling, leaf drying and spikelet sterility 
are negatively correlated with grain yield under drought stress condition (Girish et al., 2006 and Murthy et al., 2011). Drought related traits like leaf rolling and leaf drying are negative correlated with relative water content and plant biomass whereas positively correlated with proline content (Beena et al., (2012). There is positive correlations between proline content, soluble protein content, chlorophyll stability index, stress recovery and relative water content with biomass under drought stress.

The root growth during initial drought stress is enhanced for better access to water and dehydration avoidance. However, prolonged drought results in root shrinkage, anatomical deformations, and weak root-soil contact that limits water and ion supply. In legume crops, the stresses decrease nodule size, weight and nitrogenase activity. The changes in root growth and distribution reduces shoot growth and functions as an effect of root-to-shoot signaling with contribution of plant hormones and other factors (nitrogen, calcium, $\mathrm{P}^{\mathrm{H}}$ ) acting as signal molecules. The seed yield and its components are significantly reduced due to drought stress. Stress at ear emergence stage caused the greatest reduction in seed yield (because of pollination susceptibility to water stress). Yadav and Bhatnagar (2001) in a study on pearl millet indicated that seed yield in stressful and non-stress environments were 828-1136 $\mathrm{kgha}^{-1}$ and 3123-3942kg.ha ${ }^{-1}$, respectively. Mahalakshmi \& Bidinger (1985) reported that drought stress at seed filling stage reduced seed yield up to $50 \%$.

\subsection{Physiological Response of Plants under Drought Stress}

Drought stress is associated with both destructive and constructive elements and it is a driving force improving resistance and adaptive evolution (Larcher, 1987). The drought stress leads to hardening of plants by establishing a new physiological standard, which is an optimum stage of physiology under the changed environmental conditions. Based on the differences in behavior of the photosynthetic apparatus during desiccation, there are two groups of desiccation tolerant plants were distinguished. These are homo-chlorophyllous desiccation tolerant and poikilochlorophyllous desiccation tolerant (Gaff, 1989). The most essential difference between homochlorophyllous desiccation tolerant and poikilochlorophyllous desiccation tolerant plants during desiccation seems to be that the photosynthetic apparatus of the homochlorophyllous desiccation tolerant plants is retained in a recoverable form, while in poikilochlorophyllous desiccation tolerant plants the chlorophylls and thylakoid systems are degraded and need to be fully reconstituted and revived (Tuba et al., 1996).

Drought stress affects the transpiration rates, force stomatal closure, decrease water potential in plant tissue, decrease in photosynthesis and growth inhibition, accumulation of abscisic acid (ABA), proline, mannitol, sorbitol, formation of radical scavenging compound and synthesis of new proteins and mRRNAs. In addition to these, physiological responses plants also undergo morphological changes. One of the largest is the adaptation of plants and chloroplasts to high light and low light (shade exposure). This sun-type or shade-type chloroplast adaptation is also induced by many other stress factors including drought (Lichtenthaler et al., 1981).

\subsection{Mechanisms of Drought Resistance of Crop Plants}

Drought stress is a serious agronomic problem contributing to severe yield losses worldwide. This agricultural constraint may nevertheless be addressed by developing crops that are well adapted to drought prone environments. The mechanisms that enable crops to survive under the harsh conditions are complex and not well understood. Previous researches suggested three general strategies for plant survival in drought environments (Ludlow and Muchow, 1990). These strategies are drought escape, avoidance and tolerance. However, crop plants use more than one mechanism at a time to resist drought. Plants respond and adapt to survive under drought stress by the induction of various morphological, physiological and biochemical responses. The identification of genetic factors involved in plant response to drought stress provides a strong foundation for improving drought tolerance. Plants have evolved a series of mechanisms at the morphological, physiological, biochemical, cellular, and molecular levels to overcome water deficit or drought stress conditions. There are several drought-related traits which include: root traits, leaf traits, osmotic adjustment capabilities, water potential, ABA content, and stability of the cell membrane are very relevant in drought resistance mechanisms.

Drought resistance is a complex trait, expression of which depends on action and interaction of different morphological (earliness, reduced leaf area, leaf rolling, wax content, efficient rooting 
system, awn, stability in yield and reduced tillering), physiological (reduced transpiration, high wateruse efficiency, stomatal closure and osmotic adjustment) and biochemical (accumulation of proline, polyamine, trehalose, increased nitrate reductase activity and increased storage of carbohydrate) characters. Effects of drought was reflected in reduced accumulation in plant mass, shorter first internode, increased tillering, early senescence and premature death, and fruit discoloration and damage in various plants (Vahid et al., 2007; Zlatev and Lidon, 2012). The dry biomass is relatively lower as compared to fresh plant biomass (Augé et al., 2001; Zlatev and Lidon, 2012).

Water stressed compared to well-watered plants showed a higher value of the maximum leaf bulk elastic modulus, probably due to lower solute potentials at full turgor rather than the increase in the cell wall rigidity (Zlatev and Lidon, 2012). The high yielding varieties are better than low yielder varieties under severe drought and it is considered as drought resistant or tolerant. Drought resistant variety is developed when crop demand for water is not met by the supply and water status is decreased. Drought resistance in terms of the physiology involved interacts with the magnitude and the timing of the stress. Timing here refers to the stage of plant development when stress occurs. For example, drought resistance in seedlings grown in a pot has nothing to do with drought resistance during grain filling in the field.

\subsubsection{Drought Escape}

Drought escape is the ability of plants to avoid drought by completing their life cycles before the onset of a dry period to sustain some reproduction (Manavalan et al., 2017). This mechanism involves rapid phenological development (early flowering and early maturity), developmental plasticity (variation in duration of growth period depending on the extent of water-deficit) and remobilization of parenthesis assimilates to grain. Escape from drought is attained by the shortening of life cycle or growing season, allowing plants to reproduce only in the favorable environment conditions. Shortening of flowering time, days to $50 \%$ flowering can lead to drought escape. Crop duration $\mathrm{x}$ genotype $\mathrm{x}$ environment determine the ability of plant to escape from drought. Drought escape occur when plant complete developmental stages with favorable soil moisture and optimum environmental conditions (Araus et al., 2002).

\subsubsection{Drought Avoidance}

Drought avoidance refers to the mechanisms that reduce water loss from plants, due to stomatal transpiration, and water uptake through the extensive and prolific root system (Kavar et al., 2007). The root characters such as biomass, length, density and depth are the main drought avoidance traits that contribute to yield under terminal drought environments (Turner et al., 2001). A deep and thick root system is helpful for extracting water from considerable depths (Kavar et al., 2007). The drought avoidance mechanism avoids a low water status in tissues during water stress by maintaining cell turgor and cell volume. This is achieved either through aggressive water uptake by an extensive root system, leaf rolling, through reduction of water loss from stomatal transpiration and other nonstomatal pathways such as cuticular transpiration (Ludlow and Muchow, 1990).

Drought avoidance is the ability of plants to maintain relatively high tissue water potential despite a shortage of soil-moisture. Mechanisms for improving water uptake, storing in plant cell and reducing water loss confer drought avoidance. Drought avoidance is performed by maintenance of turgor through increased rooting depth, efficient root system and by reduction of water loss through reduced epidermal (stomatal and lenticular) conductance, reduced absorption of radiation by leaf rolling or folding, and reduced evaporation surface (leaf area). The mechanisms that confer drought resistance by reducing water loss (such as stomatal closure and reduced leaf area) usually result in reduced assimilation of carbon dioxide.

\subsubsection{Drought Tolerance}

Drought tolerance is defined as the ability to grow flower and display less yield penalty under the limited water regimes. In order to overcome the drought stress, tolerant plants initiate defense mechanisms against water deficit (Chaves and Oliveira, 2004). This mechanism involves physiological traits including osmotic adjustment, antioxidant capacity and genetic components such as pre-flowering drought tolerance and post anthesis drought tolerance (Siddique et al., 2002). Drought tolerance is the ability to withstand water-deficit with low tissue water potential. To improve drought tolerance trait, breeding requires fundamental changes in the set of desired traits and finally 
developing drought tolerant variety(Maleki et al., 2013). Plant drought tolerance involves changes at whole plant, cell, tissue, physiological and molecular and genetic levels. Manifestation of a single or a combination of inherent changes determines the ability of the plant to survive itself under limited moisture supply.

\section{CONCLUSION}

Crop yield improvement is required to meet the needs of future population growth; however abiotic stresses cause significant yield reductions throughout the world. Plant growth and productivity is determined by the several abiotic and biotic environmental factors. Among abiotic factors, drought stress is one of the major abiotic stresses, adversely affecting crop growth and mostly limits agricultural productivity worldwide. Water ability in plants, is a major driving force behind the regulation of fitness and survivality. The effect of drought stress has significant negative impact on crop productivity through affecting various plant traits as photosynthesis, respiration, water relation and biomass production. It has severe effect on the seed germination, growth, phenology, water and nutrient relations, photosynthesis, assimilate partitioning, respiration, and yield component in plants. The effect of drought stress ranges from morphological to molecular levels, which are evident as plant growth is affected at all phenological stages.

Drought is the most important abiotic factor which adversely affects growth, development and crop productivity. It is the most important challenging environmental stresses, especially in warm and dry areas of the world in causing significant yield reduction. Most of the morphological, physiological and genetical characteristics of crop plants are affected in several different ways. Some the traits affected by drought include: seed germination, seedling establishment, hypocotyl length, cell growth, shoot and root fresh and dry weight, and seed reserve utilization, number of tiller, spike, grain per plant, grain weight, delay silking, ear and kernel number per plant, harvest index, grain filling, remobilization of carbon reserve, relative water content, leaf water potential, loss in turgidity, stomatal resistance, transpiration rate, increase leaf and canopy temperature, water use efficiency, leaf expansion, impaired photosynthetic machinery, premature leaf senescence, $\mathrm{CO}_{2}$ uptake, change in photosynthetic pigment, photosynthetic apparatus, Calvin cycle enzyme, ATP synthesis, Source and sink limitation, low invertase activity, reproductive abortion, assimilate translocation, seed set and filling, improper phloem unloading, increase in root respiration, imbalance between $\mathrm{CO}_{2}$ used and utilization, Uncoupling of cytochrome, reduction in root and shoot biomass, generation of reactive oxygen species, membrane injuries, enzyme inactivation, enhanced peroxidation of membrane lipids, degradation of nucleic acids, and both structural and functional proteins.

There are three basic general strategies are suggested for plant survival in drought environments. These strategies are drought escape, avoidance and tolerance. However, crop plants use more than one mechanism at a time to resist drought. To overcome the drought stress challenge, plants develop certain efficient strategies. Such adaptation strategies are: morphological, anatomical, biochemical and molecular approaches used to adapt and defense themselves from the drought stress. Drought stress effects on plants are complex in nature and it affects all the stages of plant growth from the seed germination to reproduction. Eventually, drought is the most yields reducing factor in areas where the rain fall is erratic, unevenly distributed, and the water availability is limited to crop plants to survive and provides the anticipated potential yields. In addition to natural drought resistance mechanisms of plants, developing drought resistant or tolerant varieties is crucial in balancing future population growth and food demand all over the world.

\section{REFERENCES}

[1] Ahmad S, Ahmad R, Ashraf MY, Ashraf M, Waraich EA, 2009. Sunflower (Helianthus Annuus L.) response to drought stress at germination and seedling growth stages. Pak J Bot; 41:647-54.

[2] Alam, S.M., 1999. Nutrient Uptake by Plants under Stress Conditions. Marcel Dekker.

[3] Araus, J.L., Villegas, D., Aparicio, N., Del Moral, L.F., El Hani, S., Rharrabti, Y., Ferrio, J.P. and Royo, C., 2003. Environmental factors determining carbon isotope discrimination and yield in durum wheat under Mediterranean conditions. Crop Science, 43(1):170-180.

[4] Arjenaki, F.G., R. Jabbari, A. Morshedi, 2012. Evaluation of Drought Stress on Relative Water Content, Chlorophyll Content and Mineral Elements of Wheat (Triticum aestivum L.) Varieties. I. J. A. C.S., 4(11): 726-729.

[5] Auge R.M., Kubikova E., and Moore J.L., 2001. Foliar dehydration tolerance of mycorrhizal cowpea, soybean and bush bean. New Phytol, 151: 535-541. 
[6] Baque, M.A, Karim, A. Hamid and H. Tetsushi 2006. Effects of fertilizer potassium on Growth, Yeild and Nutrient uptake of Wheat (Tritcum aestivum) under water stress condition. South pacific Studies $27: 1$.

[7] Beena R, Thandapani, Chandrababu R., 2012. Physiomorphological and biochemical characterization of selected recombinant inbred lines of rice for drought resistance. Indian J. Plant Physiol. 17(2): 189-193.

[8] Bhatt, R.M. and N.K. Srinivasa Rao, 2005. Influence of pod load response of okra to water stress. Indian J. Plant Physiol., 10: 54-59.

[9] Blum A. 2004. Sorghum physiology. In 'Physiology and biotechnology integration for plant breeding'. (Eds HT Nguyen, A Blum) 141-223.

[10] Blum, A., 1996. Constitutive traits affecting plant performance under stress. In: Edmeades, G.O., M. Banziger, H.R. Mickelson and C.B. Pena- Valdivia (eds.), Developing Drought and Low N Tolerant Maize, 13135 .

[11] Boyer, J. S. (1976) Water deficits and photosynthesis. Water deficits and plant growth. (Ed. by T.T. Kozlowski). Vol. IV.153-190.

[12] Chaves, M.M. and Oliveira, M.M., 2004. Mechanisms underlying plant resilience to water deficits: prospects for water-saving agriculture. Journal of experimental botany, 55(407): 2365-2384.

[13] Chen K, Arora R., 2011. Dynamics of the antioxidant system during seed osmopriming, post-priming germination, and seedling establishment in Spinach (Spinacia oleracea). Plant Sci;180:212-20.

[14] Cook BI, Miller RL, Seager R. Amplification of the North American "Dust Bowl" drought through human-induced land degradation. Proc Natl Acad Sci 2009, 106:4997-5001.

[15] Ehleringer, J., 1980. Leaf morphology and reflectance in relation to water and temperature stress. Adaptation of plants to water and high temperature stress. (ed. by Neil C. Turner and Paul J. Kramer), 295-308.

[16] Farooq, M., A. Wahid, N. Kobayashi, D. Fujita and S.M.A. Basra, 2009. Plant drought stress: effects, mechanisms and management. Agron. Sustain. Dev., 29: 185-212.

[17] Farooq, M., S.M.A. Basra, A. Wahid, Z.A. Cheema, M.A. Cheema and A. Khaliq, 2008. Physiological role of exogenously applied glycinebetaine in improving drought tolerance of fine grain aromatic rice (Oryza sativa L.). J. Agron. Crop Sci., 194: 325-333.

[18] Farquhar, G. D., Wong, S. C., Evans, J. R. and Hubick, K. T. (1989) Photosynthesis and gas exchange. Plants under stress. Biochemistry, physiology and ecology and their application to plant improvement, 47- 69.

[19] Fathi, A. and Tari, D.B., 2016. Effect of drought stress and its mechanism in plants. International Journal of Life Sciences, 10(1): 1-6.

[20] Gaff, D. F., 1989. Responses of desiccation tolerant "resurrection" plants to water stress. In: Structural and functional responses to environmental stresses. Eds. Kreeb, K.H., Richter, H., T.M. Hinckley. SPB Acad. Publ. Bv, The Hague, 255-268.

[21] Gaspar, T., T. Franck, B. Bisbis, C. Kevers, L. Jouve, J.F. Hausman and J. Dommes, 2002. Concepts in plant stress physiology. Application to plant tissue cultures. Plant Growth Regul., 37: 263-285.

[22] Girish TN, Gireesha TM, Vaishali MG, Hanamareddy BG, Hittalmani S (2006). Response of a new IR50/Moroberekan recombinant inbred population of rice (Oryzasativa L.) from an indica x japonica cross for growth and yield traits under aerobic situations. Euphytica 152:149-161.

[23] Hoerling M, Hurrell J, Eischeid J, Phillips A. Detection and attribution of twentieth-century northern and southern African rainfall change. J Clim 2006, 19:3989-4008.

[24] Hu, Y. and U. Schmidhalter, 2003. Drought and salinity: A comparison of their effects on mineral nutrition of Plants. J. Plant Nutr. Soil Sci., 168: 541-549.

[25] Jaleel, C.A., P. Manivannan, G.M.A. Lakshmanan, M. Gomathinayagam and R. Panneerselvam, $2008 \mathrm{c}$. Alterations in morphological parameters and photosynthetic pigment responses of Catharanthus roseus under soil water deficits. Colloids Surf. B: Biointerfaces, 61: 298-303.

[26] Jaleel, C.A., P. Manivannan, P.V. Murali, M. Gomathinayagam and R. Panneerselvam, 2008d. Antioxidant potential and indole alkaloid profile variations with water deficits along different parts of two varieties of Catharanthus roseus. Colloids Surf. B: Biointerfaces, 62: 312-318.

[27] Kavar T, Maras M, Kidric M, Sustar-Vozlic J, Meglic V 2007. Identification of genes involved in the response of leaves of Phaseolus vulgaris to drought stress. Mol Breed 2:159-172.

[28] Kramer, P. J. and Boyer, J. S. 1995. Water relations of plants and soils.

[29] Kumar S., Dwivedi S. K., Singh S. S., Jha S. K., Lekshmy S, Elanchezhian R., Singhand O. N. and Bhatt B. P. 2012. Identification of Drought Tolerant Rice Genotypes by Analyzing Drought Tolerance Indices and Morpho-Physiological Traits. Research Article. SABRAO Journal of Breeding and Genetics 46(2): 217-230.

[30] Larcher, W., 1987. Stress bei Pflanzen. Naturwissenschaften, 74, 158-167.

[31] Levitt, J. 1972. Responses of plants to environmental stresses. Academic Press, New York. 
[32] Li FL, Bao WK, Wu N., 2011. Morphological, anatomical and physiological responses of drought.

[33] Lichtenthaler, H. K., Buschmann, C., Doll, M., Fietz. H. J., Bach, T., Kozel, U., Meier D., U. Rahmsdorf, 1981. Photosynthetic activity, chloroplast ultrastructure, and leaf characteristics of high-light and low-light plants and of sun and shade leaves. Photosynth. Res., 2: 115-141.

[34] Ludlow, M.M. and R.C. Muchow, 1990. A critical evaluation of traits for improving crop yields in waterlimited environments. Adv Agron., 43: 107-153.

[35] Maleki, A., Naderi, A., Naseri, R., Fathi, A., Bahamin, S. and Maleki, R., 2013. Physiological performance of soybean cultivars under drought stress. Bull. Env. Pharmacol. Life Sci, 2(6): 38-44.

[36] Manavalan, L.P. and Nguyen, H.T., 2017. Drought tolerance in crops: Physiology to genomics. Plant Stress Physiol, 1:23.

[37] Mengel, K., Kirkby, E.A., Kosegarten, H. and Appel, T., 2001. The soil as a plant nutrient medium. In Principles of plant nutrition, 15-110.

[38] Mitchell JH, Siamhan D, Wamala MH, Risimeri JB, Chinyamakobvu E, Henderson SA, Fukai S. 1998. The use of seedling leaf death score for evaluation of drought resistance of rice. Field Crops Research 55:129-139. Doi: 10.1016/S0378-4290(97)00074-9.

[39] Murthy KBC, Kumar A, Hittalmani S 2011. Response of rice (Oryza Sativa L.) genotypes under aerobic situations. Electronic Journal of Plant Breeding. 2(2): 194-199.

[40] Quick, W. P., Chaves, M. M., Wendler, R., David, M., Rodrigues, M. L., Passaharinho, J. A., Pereira, J. S., Adcock, M. D., Leegood, R. C. and Stitt, M. 1992. The effect of water stress on photosynthetic carbon metabolism in four species grown under field conditions. Plant, Cell and Environment, 15: 25-35.

[41] Razmjoo, K., P. Heydarizadeh and M.R. Sabzalian, 2008. Effect of salinity and drought stresses on growth parameters and essential oil content of Matricaria chamomile. Int. J. Agric. Biol., 10: 451-454.

[42] Sacks, M.M., W.K. Silk and P. Burman, 1997. Effect of water stress on cortical cell division rates within the apical meristem of primary roots of maize. Plant Physiol., 114: 519-527.

[43] Schulze, E. D. (1986) Carbon dioxide and water vapor exchange in response to drought in the atmosphere and in the soil. Ann. Rev. Plant Physiol., 37: 247-274.

[44] Schuppler, U., He, P.H., John, P.C. and Munns, R., 1998. Effect of water stress on cell division and Cdc2like cell cycle kinase activity in wheat leaves. Plant physiology, 117(2): 667-678.

[45] Seghatoleslami, M. J., M. Kafi and E. Majidi, 2008. Effect of drought stress at different growth Stages on yield and water use efficiency of five Proso millet (panicum miliaceum 1.) Genotypes. Pak. J. Bot., 40(4): 14271432 .

[46] Shao H.B., L.Y. Chu, M.A. Shao, C. Abdul Jaleel and M. Hong-Mei, 2008. Higher plant antioxidants and redox signaling under environmental stresses. Comp. Rend. Biol., 331: 433-441.

[47] Siddique, M.R.B., Hamid, A. and Islam, M.S., 2000. Drought stress effects on water relations of wheat. Botanical Bulletin of Academia Sinica.

[48] Specht, J.E., K. Chase, M. Macrander, G.L. Graef, J. Chung, J.P. Markwell, M. Germann, J.H. Orf and K.G. Lark, 2001. Soybean response to water. A QTL analysis of drought tolerance. Crop Sci., 41: 493-509.

[49] Stahle DW, Fye FK, Cook ER, Griffin RD. Tree-ring reconstructed mega droughts over North America since AD 1300. Clim Change 2007, 83:133-149.

[50] Trenberth KE, Branstator GW, Arkin PA 1988. Origins of the North-American drought. Science 1988, 242:1640-1645.

[51] Tuba, Z., Lichtenthaler, H., Csintalan, Z., Nagy, Z., K. Szente, 1996. Loss of chlorophylls, cessation of photosynthetic $\mathrm{CO} 2$ assimilation and respiration in the poikilochlorophyllous plant Xerophyta scabrida during desiccation. Physiol. Plant., 96, 383-388.

[52] Turner, N.C., Wright, G.C. and Siddique, K.H.M., 2001. Adaptation of grain legumes (pulses) to waterlimited environments. Advances in Agronomy, 71:193-231.

[53] Vahid A., 2007. Physiological implications of metabolites biosynthesis in net assimilation and heat stress tolerance of sugarcane sprouts. J. Plant Res., 120:219-222.

[54] Wang WB, Kim YH, Lee HS, Kim KY, Deng XP, Kwak SS. Analysis of antioxidant enzyme activity during germination of alfalfa under salt and drought stresses. Plant Physiol Bioch 2009; 47:570-7.

[55] Wilhite DA. Drought as a natural hazard: concepts and definitions. In Wilhite DA, ed. Droughts: Global Assessment. London: Routledge; 2000: 3-18.

[56] Wong, S. C., Cowan, I. R. and Farquhar, G. D. 1985. Leaf conductance in relation to rate of $\mathrm{CO}_{2}$ Assimilation. II. Effects of short-term exposures to different photon flux densities. Plant Physiol., 78: 826-829.

[57] Wu, Q.S., R.X. Xia and Y.N. Zou, 2008. Improved soil structure and citrus growth after inoculation with three arbuscular mycorrhizal fungi under drought stress. European J. Soil Biol., 44: 122-128. 
[58] Wullschleger, S.D., T.M. Yin, S.P. Difazio, T.J. Tschaplinski, L.E. Gunter, M.F. Davis and G.A. Tuskan, 2005. Phenotypic variation in growth and biomass distribution for two advanced-generation pedigrees of hybrid poplar. Canadian J. For. Res., 35: 1779-1789.

[59] Zhang, M., L. Duan, Z. Zhai, J. Li, X. Tian, B. Wang, Z. He and Z. Li, 2004. Effects of plant growth regulators on water deficit-induced yield loss in soybean. Proceedings of the 4th International Crop Science Congress, Brisbane, Australia.

[60] Zhu, J.K., 2002. Salt and drought stress signal transduction in plants. Annu.Rev. Plant Biol., 53: 247-273

[61] Zlatev Z. and Lidon F.C., 2012. An overview on drought induced changes in plant growth, water relations and photosynthesis. Emir. J. Food Agric., 24, 57-72

Citation: Temesgen Begna, “ Effects of Drought Stress on Crop Production and Productivity” International Journal of Research Studies in Agricultural Sciences (IJRSAS), 2020; 6(9), pp. 34-43, https://doi.org/10.20431/2454-6224.0609005

Copyright: (C) 2020 Authors. This is an open-access article distributed under the terms of the Creative Commons Attribution License, which permits unrestricted use, distribution, and reproduction in any medium, provided the original author and source are credited. 